\title{
Stress degradation studies and stability-indicating TLC-densitometric method of glycyrrhetic acid
}

\author{
Syed Ghulam Musharraf*, Nayab Kanwal and Qamar ul Arfeen
}

\begin{abstract}
Background: Glycyrrhetic acid, a pentacyclic triterpenoid, possesses a broad range of pharmacological activities and serves as template to synthesize many bioactive drugs. This paper describes a simple, accurate, and sensitive stability-indicating TLC densitometric method for the determination of glycyrrhetic acid and its degradation product as per the $\mathrm{ICH}$ guidelines.

Results: Separation was carried out on TLC aluminium sheet pre-coated with silica gel 60F254 using chloroform, methanol and formic acid (9:0.9:0.1, v/v). Compact spot for glycyrrhetic acid was found at $R_{\mathrm{f}}$ value of $0.42 \pm 0.03$. Densitometric analysis was carried out in the absorbance mode at $\lambda_{\max } 254 \mathrm{~nm}$. Glycyrrhetic acid was found to be stable to the exposure of base, neutral, oxidation, dry heating treatment and wet heating treatment, but showed degradation under acidic and photochemical conditions. Moreover, fragmentation pattern of glycyrrhetic acid was developed by using a positive ion electrospray ionization quadrupole time-of-flight mass spectrometry (ESI-QqTOFMS/MS) hybrid instrument. A photo-degraded product was characterized through comparison of mass spectrometric studies with glycyrrhetic acid.

Conclusion: The developed stability-indicating TLC-densitometric method can be applied for routine analysis of glycyrrhetic acid in the presence of its degradation products.
\end{abstract}

Keywords: Glycyrrhetic acid, Stress degradation, Electrospray ionization quadrupole time-of-flight mass spectrometry

\section{Background}

Glycyrrhiza glabra Linn (Fabaceae) commonly known as Licorice, used worldwide as a natural sweetener and in certain cases, used as a flavor additive in the preparative of candies and foods. Moreover, powdered Licorice root is widely used in herbal drugs in the formulation of Ayurvedic and Chinese medicines. This herb has been reported with various biological activities including antitumour [1], anti-inflamatory [2], antiulcer [3], immunomodulatory [4], antimalarial [5], and anti-hypercholesterolmic [6]. The major constitute of Licorice is glycyrrhizin, which is potassium or calcium salt of glycyrrhizic acid. Glycyrrhizin is a pentacyclic triterpenoid glycoside, which is hydrolyzed to form aglycone glycyrrhetic acid [7]. Glycyrrhetic acid has shown antimicrobial [8] and anti-tumor activities [9]. Individual and simultaneously quantification of glycyrrhizin, $18 \alpha$-glycyrrhetic acid, and $18 \beta$-glycyrrhetic acid in Licorice

\footnotetext{
* Correspondence: musharraf1977@yahoo.com

H.E.J. Research Institute of Chemistry, International Center for Chemical and Biological Sciences, University of Karachi, Karachi 75270, Pakistan
}

root and confectionary products have been developed with the help of various analytical tools including HPTLC [10-12], HPLC [13,14], microemulsion thin layer chromatography [15] and LC-ESI/MS/MS [16].

Majority of plants contain multiple compounds as active ingredients, which are frequently used in drugs. These active ingredients degraded and may alter their biological activities, therefore extensive study is required for estimation of their stability-indicating properties. The parent drug stability test guidelines (Q1AR) issued by International Conference on Harmonization (ICH) requires the stress testing to elucidate the inherent stability characteristics of the active substance. This guideline emphasizes the testing of those features which are susceptible to change during the storage under the influence of various environmental factors (temperature, light, humidity, oxidizing agent etc.). Quality, safety and efficacy must also be checked with validated stability-indicating testing methods $[17,18]$.

A considerable attention is being paid to the development of stability-indicating TLC-densitometric method 


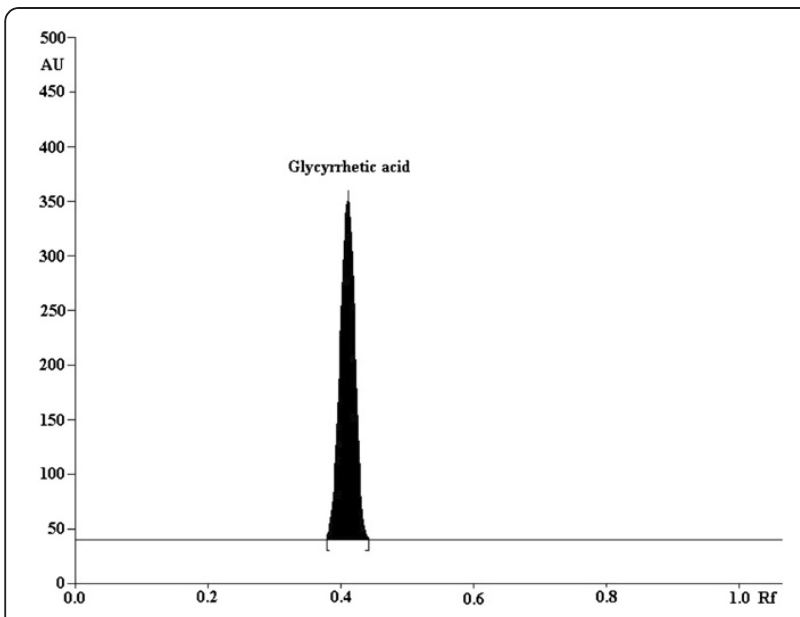

Figure 1 HPTLC Chromatogram of standard glycyrrhetic acid $\left(1000 \mathrm{ng} \mathrm{spot}^{-1}\right)$ : peak $1\left(R_{\mathrm{f}}=0.42 \pm 0.03\right)$, mobile phase; chloroform: methanol: formic acid (9:0.9:0.1).

as it is fast, reliable and accurate technique. The major advantage of HPTLC over HPLC is that a number of samples can be processed at the same time by using a minute quantity of mobile phase, thus lowering the analysis time and cost per analysis. To the best of our knowledge, there is no report found for the stability-indicating method development of glycyrrhetic acid, while stability-indicating HPTLC method of glycyrrhizic acid has been reported [19]. In continuation of our work on the chromatographic method development of pharmaceutical important compounds [20-24], this paper describes a simple, accurate, and sensitive stability-indicating TLC densitometric method for the determination of glycyrrhetic acid (an active component of Glycyrhiza glabra) and its degradation product as per the ICH guidelines. Moerover, an extensive MS/MS study of glycyrrhetic acid and its photo-degraded products was also conducted using ESI-QqTOF-MS/MS and accurate mass measurements.

\section{Experimental}

\section{Materials}

Glycyrrhetic acid was purchased from Tokyo chemical Industry (TCI, Japan). Roots (S-1) and commercial extract (S-2) of Glycyrrhiza glabra were purchased from the local market. Precoated silica gel aluminum sheets $(60 \mathrm{~F} 254,20 \mathrm{~cm} \times 20 \mathrm{~cm})$ were perchased from Merck (Germany). Sodium hydroxide was purchased from BioM Laboratories (Cerritos, USA) while hydrochloric acid $(\mathrm{HCl})$ and hydrogen peroxide $\left(\mathrm{H}_{2} \mathrm{O}_{2}, 35 \% \mathrm{v} / \mathrm{v}\right)$ were obtained from Fisher Scientific (UK). Deionized water was obtained from Millipore Milli Q Plus System (Bedford, USA). All solvents used were of HPLC grade and purchased from Merck, (Germany).

\section{Instrumentation}

\section{HPTLC analysis}

Chromatography was performed by spotting the samples in the form of bands of width $6 \mathrm{~mm}$ with a CAMAG $100 \mu \mathrm{L}$ syringe on pre-coated silica gel TLC aluminum sheets using Linomat V (CAMAG Muntenz, Switzerland) autosampler. A constant sample application rate of $0.1 \mu \mathrm{L} / \mathrm{s}$ was employed and the space between the two bands was 9.1 $\mathrm{mm} .10 \mathrm{~mL}$ of mobile phase (chloroform: methanol: formic acid, 9:1:0.1, v/v) was used for linear ascending development and chromatogram was allowed to move to a distance of $80 \mathrm{~mm}$, in twin trough glass chamber (CAMAG). The chamber saturation time for mobile phase was 10 minutes at $25 \pm 2^{\circ} \mathrm{C}$ with relative humidity $42 \pm 5 \%$. The developed TLC plate was dried with the help of air dryer for $4 \mathrm{~min}$. Video densitometry was carried out with CAMAG Reprostar III and scanning was performed on CAMAG TLC Scanner III at $\lambda_{\max } 254 \mathrm{~nm}$ which operates in reflection absorbance mode by winCATS software. Deuterium lamp with range between $190 \mathrm{~nm}$ and $400 \mathrm{~nm}$ was used as source. Evaluation was carried out via peak areas using linear regression.

\section{UPLC analysis}

UPLC analysis were performed on Agilent 1200 Series, Rapid Resolution LC (RRLC) system, comprised of an Agilent 1260 binary pump with degasser, a high performance 1260 ALS autosampler with 1290 thermostat, a thermostated column compartment (1290 TCC), and a diode-array detector VL (1260 DAD VL). Data acquisition and integration was controlled by Agilent Technologies Chem-Station software. An Agilent Zorbax XDB-C18 column $(50 \times 3 \mathrm{~mm}$ i.d., $1.8 \mu \mathrm{m})$ was used. The mobile

Table 1 Precision and accuracy for quality control standard of glycyrrhetic acid

\begin{tabular}{|c|c|c|c|c|c|c|c|c|c|}
\hline \multicolumn{7}{|c|}{ Analyst 1} & \multicolumn{3}{|c|}{ Analyst 2} \\
\hline \multirow[b]{2}{*}{ Conc. } & \multicolumn{3}{|c|}{ Intra-day } & \multicolumn{3}{|c|}{ Inter-day } & & & \\
\hline & Found ${ }^{*}$ & R.S.D. & Accuracy & Found" & R.S.D. & Accuracy & Found ${ }^{*}$ & R.S.D. & Accuracy \\
\hline (ng) & (ng) & $\%$ & $(\%)$ & (ng) & $\%$ & (\%) & (ng) & $\%$ & $(\%)$ \\
\hline 300 & $303.609 \pm 1.21$ & 0.399 & 101.203 & $303.868 \pm 1.88$ & 0.621 & 101.289 & $302.073 \pm 1.97$ & 0.650 & 100.691 \\
\hline 500 & $504.566 \pm 1.01$ & 0.200 & 100.913 & $511.555 \pm 1.62$ & 0.317 & 102.311 & $508.012 \pm 2.26$ & 0.445 & 101.602 \\
\hline 700 & $708.767 \pm 1.15$ & 0.162 & 101.252 & $709.6 \pm 1.83$ & 0.258 & 101.371 & $708.812 \pm 1.73$ & 0.244 & 101.259 \\
\hline
\end{tabular}

${ }^{*}$ Values are mean of $n=9$. 
Table 2 Robustness Study $(n=3)$

\begin{tabular}{|c|c|c|c|c|c|c|c|c|c|c|}
\hline \multirow{2}{*}{$\begin{array}{l}\begin{array}{l}\text { Standard } \\
\text { level }\end{array} \\
\text { Amount } \\
\text { (ng/spot) }\end{array}$} & \multicolumn{2}{|l|}{$\begin{array}{l}\text { Mobile phase } \\
\text { composition }\end{array}$} & \multicolumn{2}{|l|}{ Saturation time } & \multicolumn{2}{|l|}{ Nature of TLC } & \multicolumn{2}{|l|}{$\begin{array}{l}\text { Time from spotting } \\
\text { to chromatography }\end{array}$} & \multicolumn{2}{|c|}{$\begin{array}{l}\text { Time from chromatography } \\
\text { to scanning }\end{array}$} \\
\hline & $\begin{array}{c}\text { Amount detected } \\
\text { (ng } \pm \text { S.D.) }\end{array}$ & $\begin{array}{l}\text { R.S.D. } \\
\text { (\%) }\end{array}$ & $\begin{array}{c}\text { Amount detected } \\
(\mathbf{n g} \pm \text { S.D.) }\end{array}$ & $\begin{array}{l}\text { R.S.D. } \\
\text { (\%) }\end{array}$ & $\begin{array}{c}\text { Amount detected } \\
\text { (ng } \pm \text { S.D.) }\end{array}$ & $\begin{array}{l}\text { R.S.D. } \\
\text { (\%) }\end{array}$ & $\begin{array}{c}\text { Amount detected } \\
\text { (ng } \pm \text { S.D.) }\end{array}$ & $\begin{array}{l}\text { R.S.D. } \\
\text { (\%) }\end{array}$ & $\begin{array}{c}\text { Amount detected } \\
\text { (ng } \pm \text { S.D.) }\end{array}$ & $\begin{array}{c}\text { R.S.D. } \\
(\%)\end{array}$ \\
\hline 300 & $306.16 \pm 3.78$ & 1.22 & $304.45 \pm 3.66$ & 1.20 & $302.81 \pm 2.72$ & 0.89 & $303.39 \pm 2.86$ & 0.94 & $301.7 \pm 5.67$ & 1.90 \\
\hline 500 & $512.97 \pm 4.15$ & 0.81 & $514.78 \pm 3.32$ & 0.64 & $515.1 \pm 5.06$ & 0.98 & $511.88 \pm 4.01$ & 0.78 & $517.9 \pm 5.46$ & 1.05 \\
\hline 700 & $716.63 \pm 5.62$ & 0.78 & $711.2 \pm 3.82$ & 0.54 & $717.35 \pm 10.24$ & 1.42 & $720.48 \pm 4.99$ & 0.69 & $715.58 \pm 5.76$ & 0.806 \\
\hline
\end{tabular}

phase was a binary gradient system prepared from water (eluent A) and acetonitrile (eluent B), properly filtered and degassed for $15 \mathrm{~min}$ in ultra sonic bath before to use. The gradient program was: $50-60 \%$ B from 0-0.5 min, 60-65\% B from $0.5-1 \mathrm{~min}, 65-70 \% \mathrm{~B}$ from $1-2 \mathrm{~min}$, $70-75 \%$ B from $2-2.5 \mathrm{~min}, 75-100 \%$ B from $2.5-3 \mathrm{~min}$, and $100-50 \%$ B from $3-4 \mathrm{~min}$. The injection volume and flow rate were $5 \mu \mathrm{L}$ and $1 \mathrm{~mL} \mathrm{~min}^{-1}$, respectively. The assay was performed at $40^{\circ} \mathrm{C}$. The detection wavelength of DAD was $254 \mathrm{~nm}$.

\section{ESI-QqTOF-MS/MS analysis}

The standard and its photo-degraded products were dissolved in methanol and working dilution was prepared in 50:50 acetonitrile-water containing $0.1 \%$ tetrafluoro acetic acid (TFA). Analysis was performed by electrospray ionization (ESI) and collision-induced dissociation (CID), positive ion mode, on Qq-TOF-MS/MS instrument (QSTAR XL mass spectrometer Applied Biosystem/MDS Sciex, Darmstadt, Germany) coupled with 1100 HPLC system (Agilent). High-purity nitrogen gas was used as the curtain gas and collision gas delivered from Peak Scientific nitrogen generator. The ESI interface conditions were as follows: ion spray capillary voltage of $5500 \mathrm{~V}$, curtain gas flow rate $20 \mathrm{~L} \mathrm{~min}^{-1}$, nebulizer gas flow rate $30 \mathrm{~L} \mathrm{~min}{ }^{-1}$,

Table 3 Summary of validation parameters

\begin{tabular}{ll}
\hline Parameter & $\begin{array}{l}\text { Data of standard Glycyrrhetic acid } \\
\text { (at } \lambda_{\max } \text { 254nm) }\end{array}$ \\
\hline $\begin{array}{l}\text { Linearity range } \\
\text { Correlation coefficient }\end{array}$ & $200-1200 \mathrm{ng} \mathrm{spot}^{-1}$ \\
$r^{2} \pm$ SD & $0.998 \pm 0.0019$ \\
Limit of detection (LOD) & $1.56 \mathrm{ng} \mathrm{spot}^{-1}$ \\
Limit of quantitation (LOQ) & $4.74 \mathrm{ng} \mathrm{spot}^{-1}$ \\
$\mathrm{Y}=\mathrm{mx}+\mathrm{C}$ & $5.736 \mathrm{x}+664.3$ \\
Slope \pm SD & $5.76 \pm 0.58$ \\
Intercept \pm SD & $664.3 \pm 25.54$ \\
Intra-day analysis $(\mathrm{n}=3)$, & 0.253 \\
\% RSD & \\
Inter-day analysis $(\mathrm{n}=3)$, & 0.3986 \\
\% RSD & \\
Robustness & Robust \\
Specificity & Specific \\
\hline
\end{tabular}

DP1 $60 \mathrm{~V}$, DP2 $10 \mathrm{~V}$, and focusing potential of $265 \mathrm{~V}$. The collision energy was swept from 20 to $45 \mathrm{eV}$ for MS/MS analysis. Sample was introduced into the mass spectrometer using a Harvard syringe pump (Holliston, MA) at a flow rate of $5 \mu \mathrm{L} \mathrm{min}{ }^{-1}$.

\section{Calibration curve of glycyrrhetic acid}

Stock solution of glycyrrhetic acid $\left(1 \mathrm{mg} \mathrm{mL}^{-1}\right)$ was prepared in methanol. The stock solution was further diluted to obtain working standard of various concentrations including 200, 400, 600, 800, 1000, and $1200 \mathrm{ng}$ spot $^{-1}$ for calibration curve. Each working standard was spotted three times on TLC plate. The spotted plate was developed as mentioned in previous section. This practice was repeated six times to get an average standard calibration curve. The data of peak areas plotted against the corresponding concentrations were treated by linear least-square regression analysis.

\section{Method validation}

Validation of the developed HPTLC method was carried out according to the ICH guidelines for sensitivity, precision, accuracy, robustness. The sensitivity of the method was determined with respect to LOD, LOQ, and correlation coefficient. Working solutions containing 200-1200 ng of glycyrrhetic acid were spotted on TLC aluminum sheet. In order to estimate limit of detection and limit of quantitation, calibration curve was used and were calculated by using following formula: $\mathrm{LOD}=3.3 \delta / \mathrm{S}, \mathrm{LOQ}=10 \delta / \mathrm{S}$ where, $\delta=$ the residual standard deviation of regression line or the standard deviation of Y-intercept of regression line, $\mathrm{S}=$ the slope of the calibration curve. The LOD and LOQ were calculated as 3 and 10 times of the noise level, respectively. Furthermore, both were experimentally determined by diluting the known concentration of glycyrrhetic acid standard until the average responses were approximately three and ten times of the standard deviation of the responses for six replicate determinations. For method precision, the Intra- and inter-day variation for the determination of glycyrrhetic acid were carried out at three different concentration levels of 300, 500 and $700 \mathrm{ng} \mathrm{spot}^{-1}$. Repeated analyses were carried out in a same day for intraday analysis while the same practice was repeated next day for inter-day analysis. Intra- and inter-day analyses were 


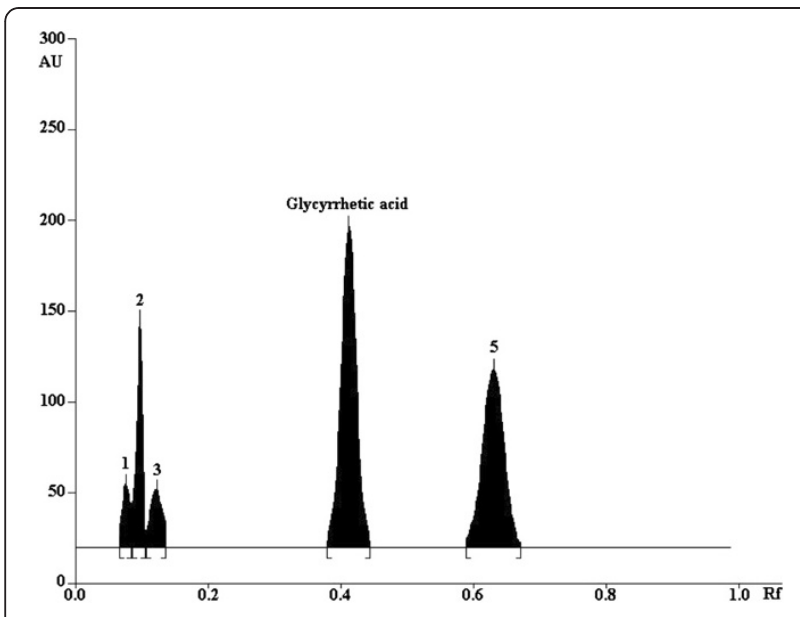

Figure 2 HPTLC Chromatogram of acid $(5 \mathrm{~N} \mathrm{HCl}$, reflux for $2 \mathrm{~h}$ at $\left.80^{\circ} \mathrm{C}\right)$ treated glycyrrhetic acid: peak 1 , degradant $\left(R_{\mathrm{f}}=0.08\right)$; peak 2, degradant $\left(R_{\mathrm{f}}=0.1\right)$; peak 3, degradant $\left(R_{\mathrm{f}}=0.12\right)$; peak 4, glycyrrhetic acid $\left(R_{\mathrm{f}}=0.42\right)$; peak 5, degradant $\left(R_{\mathrm{f}}=0.64\right)$.

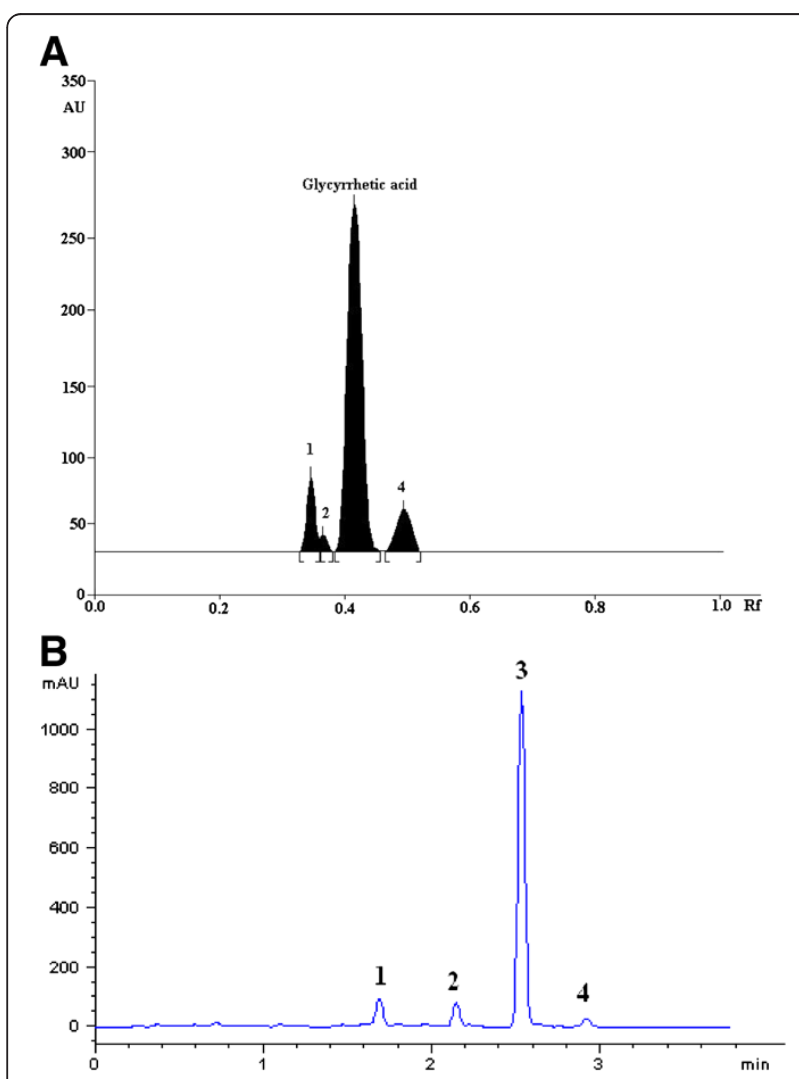

Figure 3 HPTLC Chromatogram (A) and UPLC chromatogram (B) of photo-degraded standard glycyrrhetic acid kept in sunlight for $24 \mathrm{hr}(1000 \mathrm{ng} / \mathrm{spot})$ : peak 1 , degradant $\left(R_{\mathrm{f}}=0.35\right.$ and $\left.R_{\mathrm{t}}=1.687\right)$; peak 2, degradant $\left(R_{\mathrm{f}}=0.38\right.$ and $\left.\mathrm{R}_{\mathrm{t}}=2.142\right)$; peak 3, glycyrrhetic acid $\left(R_{\mathrm{f}}=0.42\right.$ and $\left.R_{\mathrm{t}}=2.531\right)$; peak 4, degradant $\left(R_{\mathrm{f}}=0.49\right.$ and $\left.\mathrm{R}_{\mathrm{t}}=2.916\right)$. performed to check the repeatability and reproducibility of the method, respectively and results were statistically evaluated in terms of \% R.S.D. In order to check the robustness, following parameters were intentionally changed within the range of $\pm 5 \%$ at three different concentration levels (300, 500 and 700 ng); mobile phase composition, time from spotting to chromatography, time from chromatography to scanning and chamber saturation time and using different type of TLC plates. Licorice root extract was prepared according to Cui Shufen et al. [15]. All samples were spotted on TLC plate and developed as mentioned in previous section. The accuracy of the method was assessed by performing recovery study at three different levels of glycyrrhetic acid (50\%, 100\%, and 150\%).

\section{Preparation of forced degradation products}

Stress degradation studies were performed using parallel synthesizer (Smart Start Synthesizer, Chem Speed Ltd., Switzerland) with sixteen reaction vessels. Stock solution containing $100 \mathrm{mg}$ of glycyrrhetic acid in $100 \mathrm{~mL}$ of methanol was prepared. This stock solution $\left(1 \mathrm{mg} \mathrm{mL}^{-1}\right)$ was used for forced degradation studies in parallel synthesizer by refluxing the reaction mixtures for two hours at $80^{\circ} \mathrm{C}$. After the reactions were completed, all the solutions were preserved at $-20^{\circ} \mathrm{C}$. Average peak areas of active components were analyzed after triplicate analysis.

For acidic hydrolysis, $3 \mathrm{~mL}$ of methanolic stock solution of glycyrrhetic acid $\left(1 \mathrm{mg} \mathrm{mL}^{-1}\right)$ were mixed with $3 \mathrm{~mL}$ of each $1 \mathrm{~N}$ and $5 \mathrm{~N} \mathrm{HCl}$ separately and the resultant mixture solutions were refluxed for two hours at $80^{\circ} \mathrm{C}$ in the dark, in order to prohibit the possible degradative effects of light. 2 $\mu \mathrm{L}\left(1000 \mathrm{ng} \mathrm{spot}^{-1}\right)$ of $1 \mathrm{~N}$ and $5 \mathrm{~N} \mathrm{HCl}$ treated solutions of glycyrrhetic acid were applied on TLC sheet in triplicate and densitogram were developed. For alkaline hydrolysis, $3 \mathrm{~mL}$ of methanolic stock solution of glycyrrhetic acid $\left(1 \mathrm{mg} \mathrm{mL}^{-}\right.$ ${ }^{1}$ ) were mixed with $3 \mathrm{~mL}$ of each $0.1 \mathrm{~N}, 1 \mathrm{~N}$ and $5 \mathrm{~N} \mathrm{NaOH}$ separately and the resultant mixture solutions were refluxed for two hours at $80^{\circ} \mathrm{C}$ in the dark. $2 \mu \mathrm{L}\left(1000 \mathrm{ng} \mathrm{spot}^{-1}\right)$ of $0.1 \mathrm{~N}, 1 \mathrm{~N}$ and $5 \mathrm{~N} \mathrm{NaOH}$ treated solutions of glycyrrhetic acid were applied on TLC sheet in triplicate and densitogram were developed. For neutral hydrolytic condition, 3 $\mathrm{mL}$ of methanolic stock solution of glycyrrhetic acid $(1 \mathrm{mg}$ $\mathrm{mL}^{-1}$ ) were mixed with $3 \mathrm{~mL}$ of milli $\mathrm{Q}$ water and the resultant solution was refluxed for two hours at $80^{\circ} \mathrm{C}$ in the dark. $2 \mu \mathrm{L}\left(1000 \mathrm{ng} \mathrm{spot}^{-1}\right)$ of treated solution of glycyrrhetic acid was applied on TLC sheet in triplicate and densitogram were developed. For wet heating, $3 \mathrm{~mL}$ of methanolic stock solution of glycyrhhetic acid was refluxed for two hours at $80^{\circ} \mathrm{C}$ in the dark. $1 \mu \mathrm{L}\left(1000 \mathrm{ng}\right.$ spot $\left.^{-1}\right)$ of resultant solutions were applied on TLC sheet in triplicate and densitogram were developed. Oxidative degradation was carried out by taken $3 \mathrm{~mL}$ stock solutions of glycyrrhetic acid mixed with 3 $\mathrm{mL}$ of $\mathrm{H}_{2} \mathrm{O}_{2}(35 \% \mathrm{v} / \mathrm{v})$ and the resultant solutions were refluxed for two hours at $80^{\circ} \mathrm{C}$ in the dark and $2 \mu \mathrm{L}(1000$ 
Table 4 Summary of stress degradation studies of glycyrrhetic acid

\begin{tabular}{|c|c|c|c|c|}
\hline Degradation conditions & Time (hour) & $R_{\mathrm{f}}$ of degraded products & Compound remained (ng /1000ng \pm S.D., $n=3$ ) & $\%$ Recovery \\
\hline \multicolumn{5}{|l|}{ Acidic hydrolysis ${ }^{a}$} \\
\hline $1 \mathrm{~N} \mathrm{HCl}$ & 2 & $0.08,0.1,0.64$ & $362.19 \pm 7.7$ & 36.21 \\
\hline $5 \mathrm{~N} \mathrm{HCl}$ & 2 & $0.08,0.1,0.12,0.64$ & $253.83 \pm 1.5$ & 25.38 \\
\hline \multicolumn{5}{|l|}{ Basic hydrolysis ${ }^{a}$} \\
\hline $0.1 \mathrm{~N} \mathrm{NaOH}$ & 2 & Not detected & $999.9 \pm 5.2$ & 99.9 \\
\hline $1 \mathrm{~N} \mathrm{NaOH}$ & 2 & Not detected & $892.9 \pm 11$ & 89.2 \\
\hline $5 \mathrm{~N} \mathrm{NaOH}$ & 2 & Not detected & - & $100^{b}$ \\
\hline \multicolumn{5}{|l|}{ Oxidation } \\
\hline $35 \% \mathrm{v} / \mathrm{v} \mathrm{H}_{2} \mathrm{O}_{2}{ }^{\mathrm{a}}$ & 2 & Not detected & $993.07 \pm 5.5$ & 99.3 \\
\hline Oxidation at room temp & 24 & Not detected & $987.8 \pm 6.4$ & 98.7 \\
\hline Neutral hydrolysis ${ }^{a}$ & 2 & Not detected & $997.09 \pm 7.7$ & 99.7 \\
\hline Wet heating ${ }^{a}$ & 2 & Not detected & $999.47 \pm 9.5$ & 99.9 \\
\hline Dry heating & 4 & Not detected & $999.58 \pm 6.2$ & 99.9 \\
\hline Photostability- daylight & 24 & $0.35,0.38,0.49$ & $663.74 \pm 5.1$ & 66.3 \\
\hline
\end{tabular}

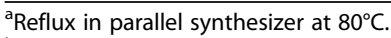

${ }^{b}$ Recover in salt form.

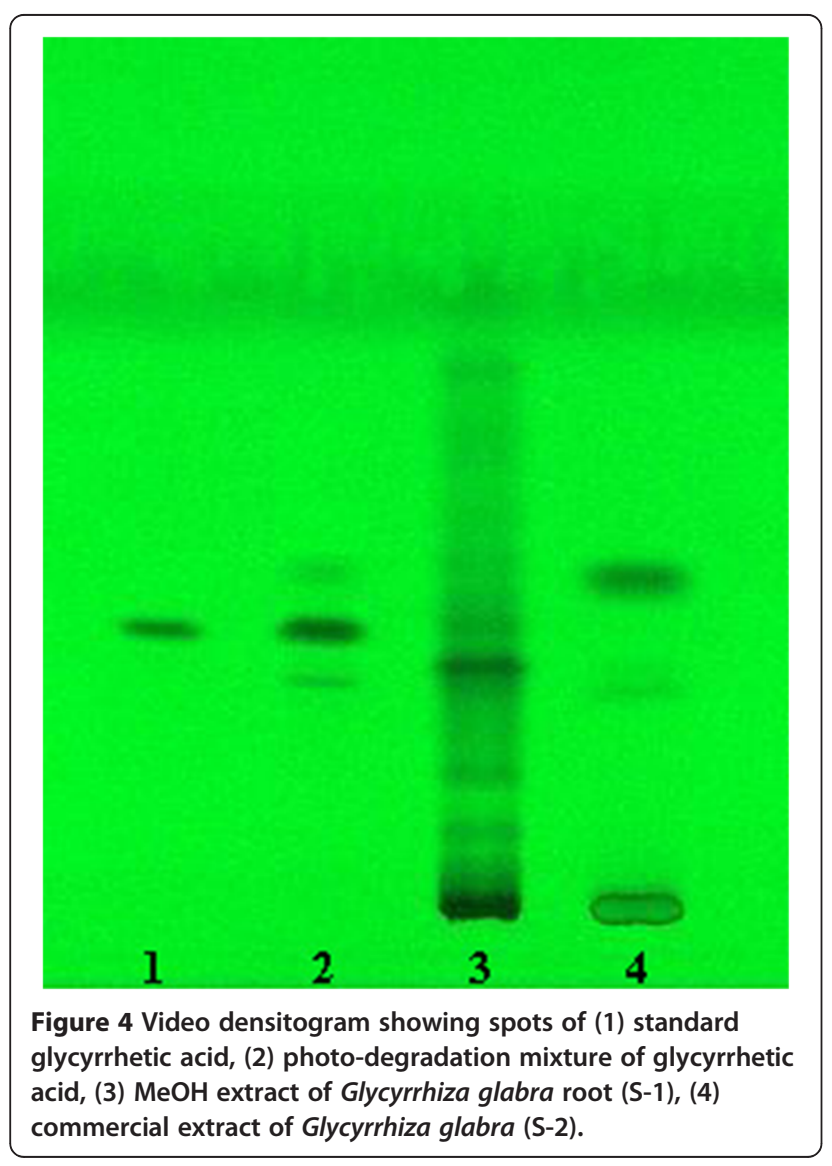

ng $\operatorname{spot}^{-1}$ ) of resultant solutions were applied on TLC sheet in triplicate and densitogram were developed.

Photo-degradation studies were carried out by the exposure of stock solution of glycyrrhetic acid to direct sunlight for three days from 8 to $18 \mathrm{hrs}$ at $30 \pm 2^{\circ} \mathrm{C} .1 \mu \mathrm{L}(1000 \mathrm{ng}$ spot $^{-1}$ ) of resultant solutions were applied on TLC sheet in triplicate and densitogram were developed. Dry heating was performed by keeping standard glycyrrhetic acid in oven at $90^{\circ} \mathrm{C}$ for $4 \mathrm{hrs} .1 \mathrm{mg}$ of treated standard was dissolved in $2 \mathrm{~mL}$ of methanol and $2 \mu \mathrm{L}\left(1000 \mathrm{ng} \mathrm{spot}^{-1}\right)$ of resultant solution of glycyrrhetic acid was applied on TLC plate in triplicate and densitogram were developed. For oxidation reaction at room temperature, $3 \mathrm{~mL}$ stock solution of glycyrrhetic acid was mixed with $3 \mathrm{~mL}$ of $\mathrm{H}_{2} \mathrm{O}_{2}$ $(35 \% \mathrm{v} / \mathrm{v})$ and the resultant solutions was kept for 24 hours at room temperature. $2 \mu \mathrm{L}\left(1000 \mathrm{ng} \mathrm{spot}^{-1}\right)$ of resultant solutions were applied on TLC sheet in triplicate and densitogram were developed.

\section{Results and discussion}

\section{Method optimization}

The TLC procedure was optimized with a view to develop stability-indicating assay method. Both the standard and degraded products were spotted on the TLC plates and developed in different solvent systems. Different mobile phases were tried to resolve glycyrrhetic acid from its degraded product. Different compositions of mobile phase and resulting $R_{\mathrm{f}}$ values of standards are summarized in (see Additional file 1: Table S1). Suitable separation with best resolution was achieved with chloroform: methanol: formic acid in the ratio of (9:0.9:0.1, v/v) which showed sharp and symmetrical peaks with $R_{\mathrm{f}}$ value of glycyrrhetic acid at $0.42 \pm 0.03$ (Figure 1). Well defined spots were 
Table 5 LC-ESI-MS/MS analysis of photo-degradation mixture of glycyrrhetic acid

\begin{tabular}{lcccccc}
\hline Peak & Rt $(\mathbf{m i n})$ & Proposed formula & Observed mass & Calculated mass & Error (ppm) & Characteristic MS/MS fragment ions \\
\hline Peak 1 & 1.687 & $\mathrm{C}_{30} \mathrm{H}_{45} \mathrm{O}_{5}$ & 485.3263 & 485.3261 & 0.3601 & $467,449,431,421,403,385,259,233,187$ \\
Peak 2 & 2.142 & $\mathrm{C}_{30} \mathrm{H}_{47} \mathrm{O}_{5}$ & 487.3450 & 487.3423 & 5.4374 & $451,423,405,387,317,271,235,189,175$ \\
$\begin{array}{l}\text { Glycyrrhetic acid } \\
\text { (Peak 3) }\end{array}$ & 2.531 & $\mathrm{C}_{30} \mathrm{H}_{47} \mathrm{O}_{4}$ & 471.3488 & 471.3468 & 4.0588 & $453,425,407,389,317,271,263,235,217$, \\
Peak 4 & & & & & 189,149 \\
\hline
\end{tabular}

obtained when the chamber was saturated with the mobile phase for $10 \mathrm{~min}$ at room temperature. The linear regression data for the calibration curve $(n=6)$ showed a good linear relationship with $r^{2} \pm \mathrm{SD}=0.998 \pm 0.0019$ over concentration range of 200-1200 ng spot ${ }^{-1}$ with respect to the peak area. Calibration curve for glycyrrhetic acid is shown in (Additional file 1: Figure S1).

\section{Method validation}

Repeatability and reproducibility of the method was determined using intra and inter-day analysis. The \% relative standard deviation (R.S.D. \%) for glycyrrhetic acid were found to be less than $1 \%$ which shows good precision of proposed method (Table 1). Limit of detection at 3:1 signal to noise ratio was found to be $1.56 \mathrm{ng}$ spot $^{-1}$ while limit of quantification at 10:1 signal to noise ratio was found to be $4.74 \mathrm{ng} \mathrm{spot}^{-1}$, which indicate the adequate sensitivity of the method. For robustness analysis, the standard deviation of standard levels $(300,500$ and $700 \mathrm{ng}$ ) was estimated for each parameter. Mean \% R.S.D. was 0.94 for varying in mobile phase composition, 0.79 for varying chamber saturation time, 1.73 for the use of different TLC plates, 2.41 for varying time from spotting to chromatography, 1.25 for varying time from
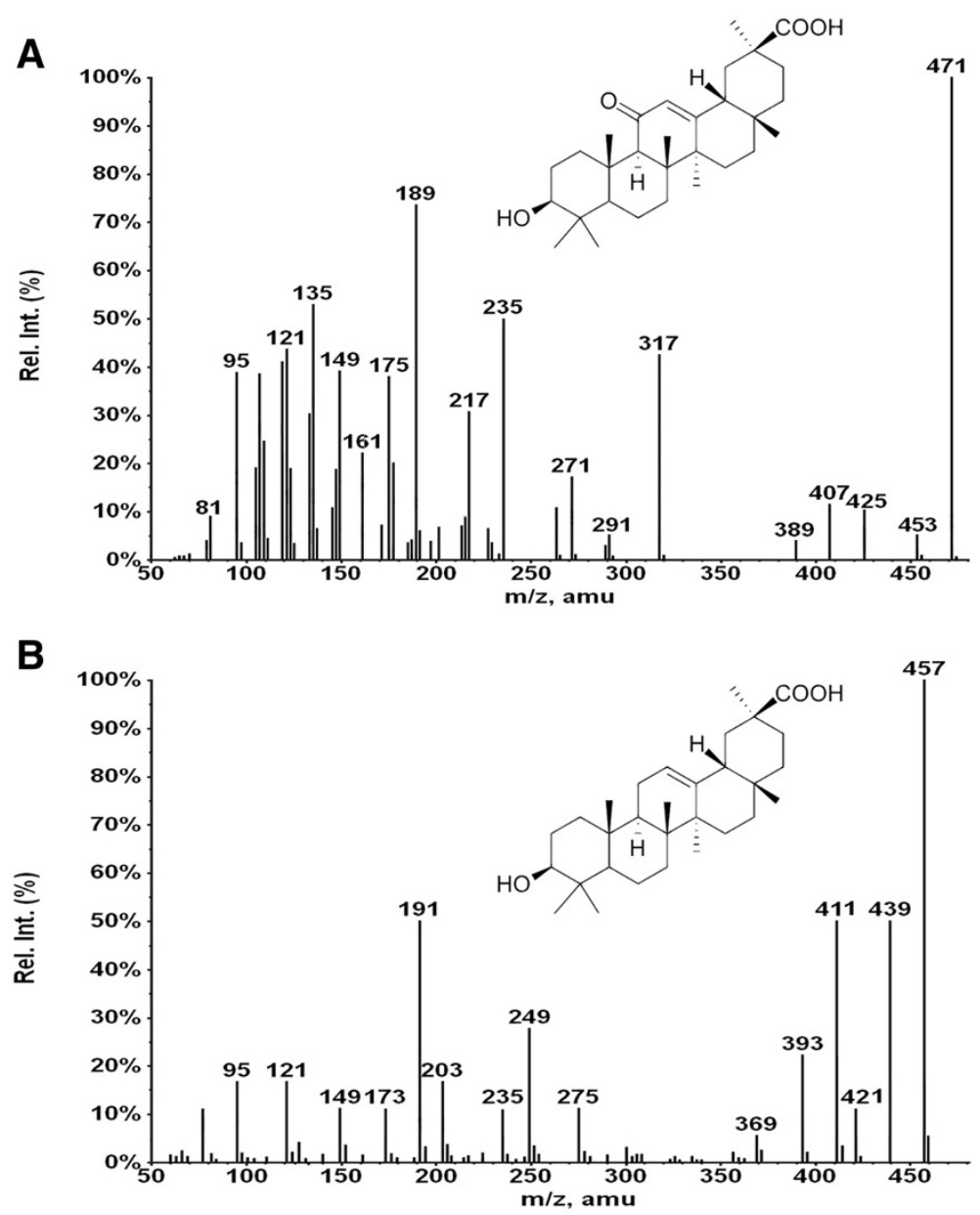

Figure 5 CID-MS/MS spectra of (a) glycyrrhetic acid and (b) its photo-degradation products, peak 4. 


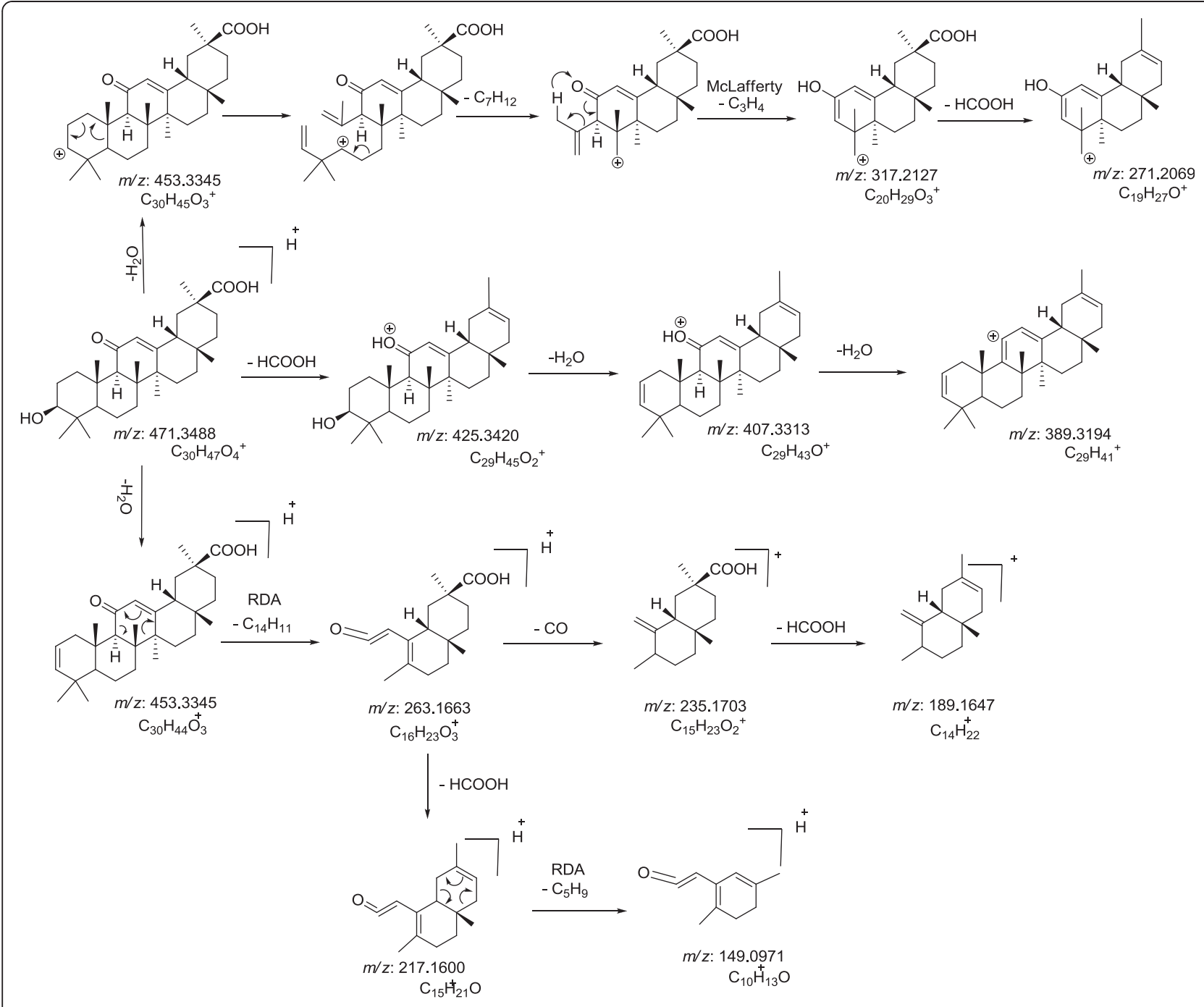

Scheme 1 Proposed CID-MS/MS fragmentation pathway of glycyrrhetic acid.

chromatography to scanning (Table 2). Spiking studies showed recovery of glycyrrhetic acid (96.7- 101.5\%) in Licorice root extract ([see Additional file 1: Table S2]). The linear regression data and the method validation results are summarized in Table 3.

\section{Stability-indicating property}

The chromatogram of glycyrrhetic acid treated with acid and sunlight showed well-separated peak of glycyrrhetic acid as well as some additional peaks (Figure 2, 3A). No degradation was observed after exposing the glycyrrhetic acid to stressed conditions of base, neutral, hydrogen peroxide, wet heating, and dry heating. Results of the stress degradation studies are summerized in Table 4. Glycyrrhetic acid showed $63.7 \%$ and $74.6 \%$ degradation under $1 \mathrm{~N} \mathrm{HCl}$ and $5 \mathrm{~N} \mathrm{HCl}$ conditions, respectively. Degraded peaks were observed at $R_{\mathrm{f}} 0.08,0.1$ and 0.64 (major), while in strong acidic medium $(5 \mathrm{~N} \mathrm{HCl})$ an additional peak generated at $R_{\mathrm{f}} 0.12$. Peak observed at $R_{\mathrm{f}}$ 0.64 was the artifact of glycyrrhetic acid that is glycyrrhetic acid methyl ester, which was confirmed by HR-EIMS and ${ }^{1} \mathrm{H}$ NMR. Under photochemical conditions, glycyrrhetic acid showed $33.7 \%$ degradation, while the degraded products were observed at $R_{\mathrm{f}} 0.35,0.38,0.49$. Under basic hydrolysis, salt was formed. UPLC chromatogram of glycyrrhetic acid treated with acid, base, and neutral are shown in (see Additional file 1: Figure S2). Moreover, screening of Licorice root extract (S-1) and its commercially available extract $(\mathrm{S}-2)$ showed the presences of its phtoto-degraded product at $R_{\mathrm{f}}=0.49$ (Figure 4 ). 


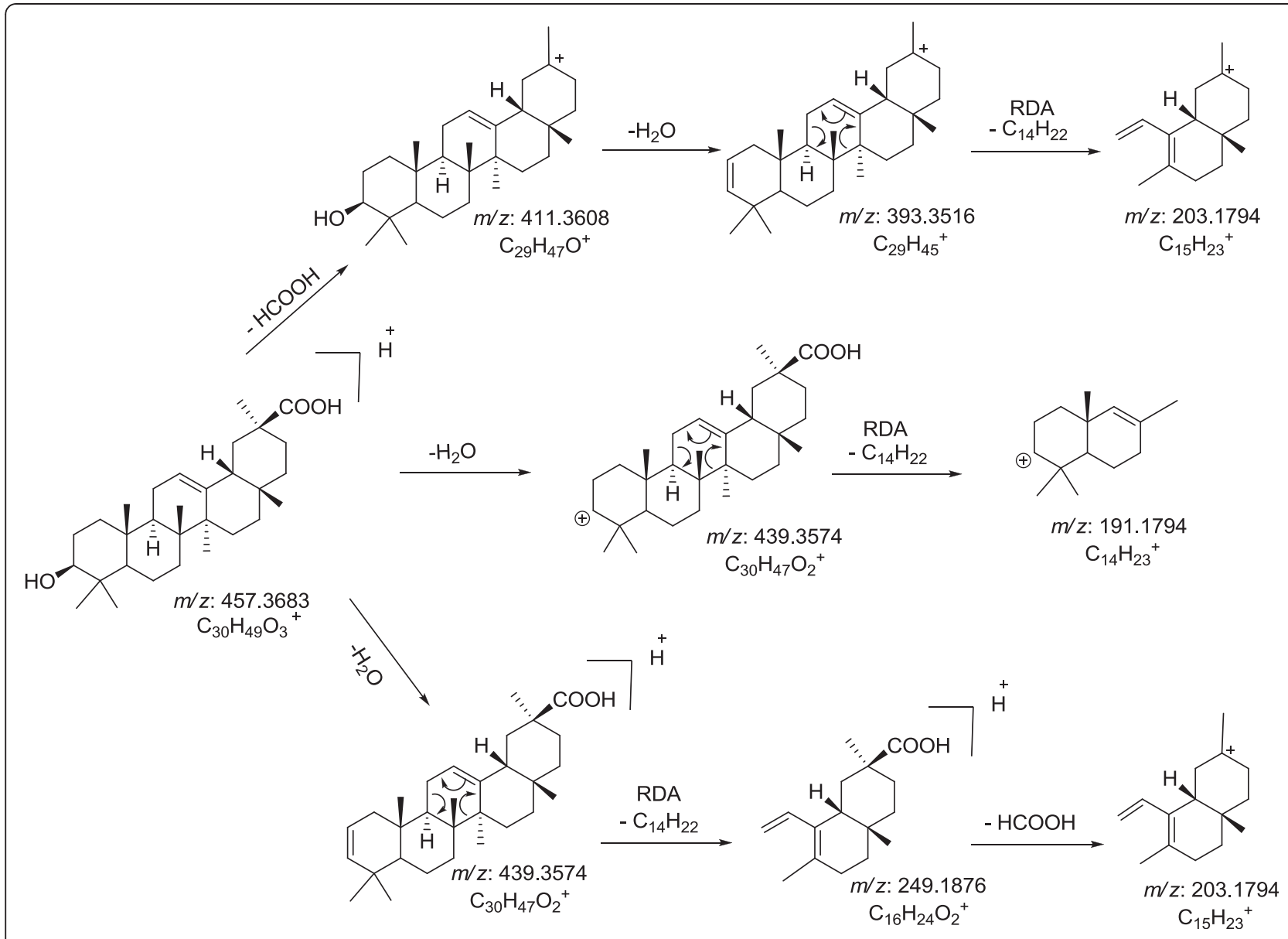

Scheme 2 Proposed CID-MS/MS fragmentation pathway of photo-degradation product of glycyrrhetic acid (Peak 4).

MS/MS analysis of glycyrrhetic acid and its photo-degradation products

UPLC analysis of photo-degradation reaction mixture of glycyrrhetic acid showed the elution of degraded products within 3 min (Figure $3 \mathrm{~B})$. The retention times $\left(\mathrm{R}_{\mathrm{t}}\right)$ and proposed formula of all the peaks are shown in Table 5. ESI-QqTOF-MS (positive mode) scan of glycyrrhetic acid and its degradation products showed peak $[\mathrm{M}+\mathrm{H}]^{+}$at $\mathrm{m} / z$ 471.3488, 485.3263, 487.3450, and 457.3636, corresponding to the molecular formulae $\mathrm{C}_{30} \mathrm{H}_{47} \mathrm{O}_{4}$ (calc. 471.3468), $\mathrm{C}_{30} \mathrm{H}_{45} \mathrm{O}_{5}$ (calc. 485.3263), $\mathrm{C}_{30} \mathrm{H}_{47} \mathrm{O}_{5}$ (calc. 487.3423) and $\mathrm{C}_{30} \mathrm{H}_{49} \mathrm{O}_{3}$ (calc. 457.3676), respectively.

The ESI-MS/MS spectrum of $[\mathrm{M}+\mathrm{H}]^{+}$ions $(\mathrm{m} / z$ 471) of glycyrrhetic acid (Peak 3), showed neutral loses of $\mathrm{H}_{2} \mathrm{O}$ and $\mathrm{HCOOH}$ from $[\mathrm{M}+\mathrm{H}]^{+}$at $m / z 453\left[\mathrm{M}+\mathrm{H}-\mathrm{H}_{2} \mathrm{O}\right]^{+}$, $m / z 425[\mathrm{M}+\mathrm{H}-\mathrm{HCOOH}]^{+}, m / z 407[\mathrm{M}+\mathrm{H}-\mathrm{HCOOH}-$ $\left.\mathrm{H}_{2} \mathrm{O}\right]^{+}, m / z 389\left[\mathrm{M}+\mathrm{H}-\mathrm{HCOOH}-2 \mathrm{H}_{2} \mathrm{O}\right]^{+}$. Fragment at $\mathrm{m} / z 263$ was supposed to be generated from $\mathrm{m} / z 453$ by retro Diel-Alder cleavage of ring $C$, and fragment at $\mathrm{m} / z$
235 was observed by the loss of CO from $m / z 263$. Subsequent neutral loss of formic acid from $\mathrm{m} / z 235$ formed the product ion at $m / z 189$. Fragment at $m / z 317$ was supposed to be formed from $m / z 453$ by the loss of $\mathrm{C}_{10} \mathrm{H}_{16}$ moiety. Subsequent neutral loss of formic acid from $\mathrm{m} / \mathrm{z}$ 317 formed the product ion at $m / z 271$. The MS/MS spectra and mechanistic fragmentation pathway of glycyrrhetic acid are shown in Figure 5a and Scheme 1, respectively.

The ESI-MS/MS spectrum of $[\mathrm{M}+\mathrm{H}]^{+}$ions of $m / z 485$ (Peak 1) and $m / z 487$ (Peak 2), showed only 14 and 16 amu increase from glycyrrhetic acid, respectively. Characteristic MS/MS fragments are summarized in Table 5. These compounds were not isolated due to further degradation during chromatographic processing, and their structures were not characterized due to miss matched fragmentation pattern with the available structure according to the molecular formula in Dictionary of Natural Products.

The ESI-MS/MS spectrum of $[\mathrm{M}+\mathrm{H}]^{+}$ions $(\mathrm{m} / z$ 457) of peak 4, eluting at retention time $\left(R_{t}\right) 2.916$ in UPLC, 
showed neutral loss of $\mathrm{H}_{2} \mathrm{O}$ and $\mathrm{HCOOH}$ from $[\mathrm{M}+\mathrm{H}]^{+}$ generated ions at $m / z 439\left[\mathrm{M}+\mathrm{H}-\mathrm{H}_{2} \mathrm{O}\right]^{+}, m / z 411[\mathrm{M}+\mathrm{H}-$ $\mathrm{HCOOH}]^{+}, m / z 393\left[\mathrm{M}+\mathrm{H}-\mathrm{HCOOH}-\mathrm{H}_{2} \mathrm{O}\right]^{+}$respectively. Fragment due to retro Diel-Alder cleavage of ring $C$ was observed at $m / z 249, m / z 203$, and $m / z 191$ from fragment $m / z 439, m / z 393$, and $m / z 439$, respectively. The MS/MS spectra and mechanistic fragmentation pathway are shown in Figure 5b and Scheme 2, respectively. Degradant (peak 4) showed only $14 \mathrm{amu}$ difference in comparison to glycyrrhetic acid, while MS/MS spectra showed similar fragmentation pattern as observed in glycyrrhetic acid. The structure of peak 4 was proposed as 11-deoxy-glycyrrhetic acid. Isolation of this degraded product was carried out and the structure was also confirmed by ${ }^{1} \mathrm{H}$ and ${ }^{13} \mathrm{C}$ NMR techniques.

All proposed fragmentation pathways have been confirmed by accurate mass measurements, which are summarized in (Additional file 1: Table S3). Degraded product was identified through comparative MS/MS studies with glycyrrhetic acid with the help of data base (Dictionary of Natural products). Degradation product was searched in the update Dictionary of Natural Products (DNP, version 20.2) on the basis of deprotonated molecular mass and respective formulae for the identification of compound. In the case of more than one match, the search was narrowed down to the plant species (Glycyrrhiza glabra) and to the other species of Glycyrrhiza.

\section{Conclusion}

The developed and validated TLC-densitometric method is precise, accurate, and stability-indicating for the quantification of glycyrrhetic acid in the presences of its degradation products. Glycyrrhetic acid showed extensive degradation in acidic and photochemical stress conditions, while stable to alkaline, neutral, oxidative, dry heating and wet heating stress conditions. A photo-degradation product was also characterized with the help of the ESI-QqTOF-MS/MS experiments combined with accurate mass measurements of precursor and fragment ions. The results showed the importance of appropriate light protection during the drug development process, storage and handling.

\section{Additional file}

Additional file 1: Figure S1. Calibration curve for glycyrrhetic acid (200$1200 \mathrm{ng} \mathrm{spot}^{-1}$ ) at $254 \mathrm{~nm}$. Figure S2. UPLC Chromatogram of (A) acidic hydrolysis: peak 1, degradant $\left(R_{t}=0.21\right)$; peak 2, degradant $\left(R_{t}=0.278\right)$; peak 3, degradant $\left(R_{t}=0.441\right)$; peak 4, glycyrrhetic acid $\left(R_{t}=2.531\right)$; peak 5, degradant $\left(R_{t}=3.776\right)$, (B) basic hydrolysis $(C)$ neutral hydrolysis. Table S1. $R_{f}$ values of glycyrrhetic acid in different mobile phases. Table S2. Recovery studies of glycyrrhetic acid ( $n=3)$. Table S3. Elemental composition of daughter ions of glycyrrhetic acid ( $m / z$ 471), and Peak 4 ( $m / z$ 457).

\section{Authors' contributions}

SGM: Participated in the experimental designing and method optimization. NK: Performed the experiments and wrote the manuscript. QA: Involved in the useful discussion and also participated in experimental work. All authors read and approved the final manuscript.

Received: 24 October 2012 Accepted: 14 January 2013

Published: 17 January 2013

\section{References}

1. Rafi MM, Vastano BC, Zhu N, Ho CT, Ghai G, Rosen RT, Gallo A, Dipaola RS: Novel polyphenol molecule Isolated from Licorice Root (Glycrrhiza glabra) Induces Apoptosis, G2/M Cell Cycle Arrest, and Bcl-2 Phosphorylation in Tumor Cell Lines. J Agric Food Chem 2002, 50:677-684.

2. Han BH, Chi HJ, Han YM, Ryu KS: Screening on the antiinflammatory activity of crude drugs. Korean J Pharmacog 1972, 4:205-209.

3. Dehpour AR, Zolfaghari ME, Samadian T, Vahedi Y: The protective effect of liquorice components and their derivatives against gastric ulcer induced by aspirin in rats. J Pharm Pharmacol 1994, 46:148-149.

4. Inada Y, Watanabe K, Kamiyama M, Kanemitsu T, Clark WS, Lange M: In-vitro immunomodulatory effects of traditional Kampo medicine (Sho-saiko-to: SST) on peripheral mononuclear cells in patients with AIDS. Biomed Pharmacother 1990, 44:17-19.

5. Misra P, Pal NL, Guru PY, Katiyar JC, Tandon JS: Antimalarial activity of traditional plants against erythrocytic stages of Plasmodium berghei. Int J Pharmacog 1991, 29:19-23.

6. Sitohy MZ, El-Massary RA, El-Saadany SS, Labib SM: Metabolic effects of Licorice roots (Glycyrrhiza glabra) on lipid distribution pattern, liver and renal functions of albino rats. Mol Nutr Food Res 1991, 35:799-806.

7. Evans WC: Trease and Evans Pharmacognosy. 15th edition. London: Saunders; 2008:300-302.

8. Kim HK, Park Y, Kim HN, Choi BH, Jeong HG, Lee DG, Hahm K: Antimicrobial mechanism of $\beta$-glycyrrhetinic acid isolated from Licorice. Glycyrrhiza glabra. Biotechnol Lett 2002, 24:1899-1902

9. Feng J, Chen W, Zhao Y, Ju X: Anti-tumor activity of oleanolic, ursolic and glycyrrhetinic acid. Open Nat Prod J 2009, 2:48-52.

10. Argekar AP, Kunjir SS: Quantitative estimation of 18-beta-glycyrrhetinic acid by HPTLC for standardization of polyherbal preparations of Licorice. J Planar Chromatogr 1996, 9:220-223.

11. Rathee P, Ratheeb S, Ahuja D: Simultaneous quantification of glycyrrhetinic acid and apigenin using HPTLC from Glycyrrhiza glabra Linn. Eurasian J Anal Chem 2010, 5:95-103.

12. Singh B, Mungara P, Nivsarkar M, Anandjiwala S: HPTLC Densitometric Quantification of glycyrrhizin, glycyrrhetinic Acid, apigenin, kaempferol and quercetin from Glycyrrhiza glabra. Chromatographia 2009, 70:1665-1672

13. Sabbionia C, Ferrantia A, Bugamellia F, Fortib GC, Raggi MA: Simultaneous HPLC analysis, with isocratic elution, of glycyrrhizin and glycyrrhetic acid in Liquorice roots and confectionery products. Phytochem Analysis 2006, 17:25-31.

14. Esmaeili S, Naghibi F, Mosaddegh M, Nader N: Determination of $18 \beta$ Glycyrrhetinic acid in glycyrrhiza glabra L. Extract by HPLC. Iran J Pharm Res 2006, 2:137-141.

15. Cui S, Fu B, Lee FS, Wang X: Application of microemulsion thin layer chromatography for the fingerprinting of Licorice (Glycyrrhiza spp.). J Chromatogr B 2005, 828:33-40.

16. Montoroa P, Maldinia M, Russo M, Postorinoc S, Piacentea S, Pizza C: Metabolic profiling of roots of Liquorice (Glycyrrhiza glabra) from different geographical areas by ESI/MS/MS and determination of major metabolites by LC-ESI/MS and LC-ESI/MS/MS. J Pharmaceut Biomed Anal 2011, 54:535-544.

17. ICH, Q1A: Stability Testing of New Drug Substances and Products, Proceedings of the International Conference on Harmonization. Geneva: IFPMA; 2000.

18. ICH Q1A (R2): Stability testing of new drug substances and products, proceedings of the International Conference on Harmonization. 2003. http://www.ich.org/fileadmin/Public_Web_Site/ICH_Products/Guidelines/ Quality/Q1A_R2/Step4/Q1A_R2_Guideline.pdf.

19. Khera D, Kohli K, Parmar N: Development and validation of stabilityindicating HPTLC method for determination of glycyrrhizic acid in bulk drug and pharmaceutical formulations. J Liq Chrom Rel Technol 2011, 34:1502-1517 
20. Musharraf SG, labal N, Gulzar U, Ali A, Choudhary MA, Rahman Au: Effective separation and analysis of E- and Z-guggulsterones in Commiphora mukul resin, guggulipid and their pharmaceutical product by high performance thin-layer chromatography-densitometric method. J Pharm Biomed Anal 2011, 56:240-245.

21. Musharraf SG, labal N, Ahmed MA, Mazhar S, Choudhary MA: Screening of $\mathrm{E}$ - and Z-guggulsterones in the gum-resin exudates of some common plants and method validation in raw, extracted, and pharmaceutical formulations of Commiphora mukul by HPLC. J Liq Chromatogra 2011, 34:2103-2117.

22. Musharraf SG, UI Arfeen Q, Shoaib M: Development and validation of TLCdensitometric method for the quantification of a steroidal drug, danazol in its pharmaceutical formulations. J Planar Chromatogr - Mod TLC 2012, 25:331-337.

23. Musharraf SG, Fatima U, Sultana R: Stress degradation studies and development of stability-indicating TLC-densitometry method for determination of prednisolone acetate and chloramphenicol in their individual and combined pharmaceutical formulations. Chem Cent J 2012, 6:7. doi:10.1186/1752-153X-6-7.

24. Musharraf SG, Gulzar U: Effective separation and simultaneous analysis of anabolic androgenic steroids (AAS) in their pharmaceutical formulations by a validated TLC-densitometry method. Chem Cent J 2012, 6:54. doi:10.1186/1752-153X-6-54.

doi:10.1186/1752-153X-7-9

Cite this article as: Musharraf et al:: Stress degradation studies and stability-indicating TLC-densitometric method of glycyrrhetic acid. Chemistry Central Journal 2013 7:9.

\section{Publish with ChemistryCentral and every scientist can read your work free of charge \\ "Open access provides opportunities to our colleagues in other parts of the globe, by allowing anyone to view the content free of charge." \\ W. Jeffery Hurst, The Hershey Company. \\ - available free of charge to the entire scientific community \\ - peer reviewed and published immediately upon acceptance \\ - cited in PubMed and archived on PubMed Central \\ - yours - you keep the copyright \\ Submit your manuscript here: \\ http://www.chemistrycentral.com/manuscript/<smiles>c1ccccc1</smiles> \\ Chemistry Central}

